\title{
Current smoking habits in British IBD patients in the age of e-cigarettes
}

\author{
Chui Chong, ${ }^{1}$ Anisha Rahman, ${ }^{1}$ Khaleel Loonat, ${ }^{1}$ Rebecca C Sagar, ${ }^{1}$ \\ Christian Philipp Selinger ${ }^{\oplus, 2}$
}

To cite: Chong C, Rahman A, Loonat $\mathrm{K}$, et al. Current smoking habits in British IBD patients in the age of e-cigarettes. BMJ Open Gastro 2019;6:e000309. doi:10.1136/ bmjgast-2019-000309

- Additional material is published online only. To view please visit the journal online (http://dx.doi.org/10. 1136bmjgast-2019-000309).

The study has previously been presented as an abstract at the 13th European Crohn's and Colitis Organisation Congress 2018 (abstract in J Crohns Colitis) and at the British Society of Gastroenterology Annual Meeting 2018 (abstract in Gut).

Received 15 April 2019 Revised 17 May 2019 Accepted 24 May 2019

Check for updates

(c) Author(s) (or their employer(s)) 2019. Re-use permitted under CC BY-NC. No commercial re-use. See rights and permissions. Published by BMJ.

${ }^{1}$ Leeds Gastroenterology Institute, Leeds Teaching Hospitals NHS Trust, Leeds, UK ${ }^{2}$ Leeds Institute of Biomedical and Clinical Sciences, University of Leeds, Leeds, UK

Correspondence to Dr Christian Philipp Selinger; christian.selinger@web.de

\section{ABSTRACT}

Background Smoking has a detrimental effect on Crohn's disease (CD) while data on ulcerative colitis (UC) are conflicting. Smoking habits have changed dramatically in the UK due to a public smoking ban and the advent of e-cigarettes. We describe current smoking rates in patients with inflammatory bowel disease (IBD) and any effects on disease course.

Methods Self-reported smoking status was elicited in outpatients with IBD, and clinical data were extracted from patient records.

Results of 465 patients (58\% CD, 42\% UC), 247 (53.1\%) were ever-smokers (37.4\% ex-smokers, $15.7 \%$ current smokers). Electronic cigarettes (e-cigarettes) were ever used by 28 patients (15 current users). All e-cigarette users had previously smoked cigarettes and 13 had stopped smoking completely. Patients with CD were more likely to currently smoke $(21.5 \%$ vs $7.7 \%, p<0.001)$ than those with UC. Ever use of biological therapy was higher in current smokers compared with never smokers $(49 \%$ vs $35 \%, p=0.034)$. The need for surgery was higher in current smokers compared with never smokers (43\% vs $25 \%, p=0.006)$. The risk of CD complications during 21-month prospective follow-up was numerically higher for current smoker versus e-cigarette users (53\% vs $17 \%$, $\mathrm{p}=0.19)$.

Compared with the general population, the proportion of current cigarette smokers $(14.9 \%$ vs $15.1 \%)$ and e-cigarette users was similar in our cohort $(4.26 \%$ vs $5.5 \%)$.

Conclusions Patients with IBD show similar smoking behaviour to the general population. E-cigarettes were used as replacement for cigarettes or by some as an intermediate step for smoking cessation. Larger, prospective studies are required to fully determine the effects of e-cigarettes on IBD.

\section{BACKGROUND}

Inflammatory bowel disease (IBD) represents a spectrum of chronic, relapsing inflammatory disorders that affect the gastrointestinal tract with Crohn's disease (CD) and ulcerative colitis (UC) making up the two most common forms. ${ }^{1}$ Although the exact aetiology of IBD still remains unknown, it is believed to be multifactorial in nature, with genetic susceptibility and environmental
Summary box

What is already known about this subject?

- Smoking has a detrimental effect on Crohn's disease while data on ulcerative colitis are conflicting. Smoking habits in the general population have changed dramatically in the UK due to a public smoking ban and the advent of electronic cigarettes (e-cigarettes).

What are the new findings?

- In parallel to the general population, smoking rates have decreased in the inflammatory bowel disease (IBD) population over the last decade. E-cigarettes are often used by patients with IBD as a replacement for cigarettes or as an interim to smoking cessation.

How might it impact on clinical practice in the foreseeable future?

- E-cigarettes may become a useful smoking cessation strategy for patients with IBD but further safety data required before implementing this into routine clinical practice.

factors playing crucial role in its pathogenesis. $^{2}$ Various environmental factors have been described to contribute to the development of IBD such as smoking habits, stress, use of non-steroidal anti-inflammatory drugs and microbial agents. ${ }^{2}$ Among these, the most established environmental factor association is for smoking. ${ }^{34}$

Cigarette smoking is mostly reported to have contradicting effects on $\mathrm{CD}$ and $\mathrm{UC}$ : smoking increases the risk of developing $\mathrm{CD}$ while it mostly exerts a protective effect on $\mathrm{UC}^{3}{ }^{34} \mathrm{UC}$ is often found to be a disease among ex-smokers and non-smokers; yet many patients with UC smoke. ${ }^{34}$ A meta-analysis by Calkins found the lifetime risk of developing UC in non-smokers to be $2.9(95 \%$ CI: 2.6 to $3.2, \mathrm{p}<0.001) .^{5}$ A meta-analysis by the US Surgeon General has shown that patients with UC were less likely to smoke than controls (relative risk $=0.54 ; 95 \%$ CI: 0.48 to 0.61$).{ }^{6}$ Conversely, smokers are shown to have an excess risk of developing $\mathrm{CD}$ with 
a pooled ORs of 2.0 (95\% CI: 1.65 to $2.47, \mathrm{p}<0.001)$ as compared with their non-smoking counterparts. ${ }^{5}$ This is supported by the latest meta-analysis by the US Surgeon General highlighting that patients with $\mathrm{CD}$ were more likely to smoke than controls (relative risk $=1.6 ; 95 \% \mathrm{CI}$ : 1.5 to 1.8$){ }^{6}$

Smoking has a significant influence on the course and treatment response of IBD. ${ }^{78}$ It is known to worsen the clinical course of $\mathrm{CD}$ with more frequent relapses and associated with greater use of immunosuppressive medications, corticosteroids and biological agents. ${ }^{79}$ Further, CD smokers have a higher tendency of developing fistulising and stricturing forms of the disease. ${ }^{10}$ On the contrary, improvements of clinical course were observed in patients with UC who smoke. ${ }^{411}$ Most studies also link smoking to lower rates of colectomy and reduced use of immunosuppressants and oral steroids in non-smokers with $\mathrm{UC}^{11}{ }^{12}$ but this was not the case in a large Australian cohort study. ${ }^{13}$

Smoking patterns in England have changed drastically in the last decade. The proportion of current smokers has dropped significantly since 2007 , from $22 \%$ to $15.1 \%$ in 2017. ${ }^{14}$ While cigarette smoking prevalence is falling steadily, the use of electronic cigarettes (e-cigarettes) is becoming more common. E-cigarettes are cylindrical-shaped devices that deliver nicotine to the smokers via aerosol formed through the heating of a mixture of liquid usually made up of nicotine, propylene glycol or glycerol (glycerine) and flavouring chemicals. ${ }^{15}$ The use of e-cigarettes among UK population has been growing steadily since they entered the European market in 2006. ${ }^{15}$ A recent Opinions and Lifestyle Survey revealed that the prevalence of e-cigarettes has grown substantially from $3.7 \%$ in 2014 to over $5 \%$ in $2017 .{ }^{14}$ This surge in popularity of e-cigarettes could be largely attributed to their role as a tool to aid smoking cessation. ${ }^{14}$ Despite that, the safety of e-cigarettes in health problems such as IBD remains unknown.

As e-cigarettes do not contain many of the ingredients known to be detrimental to human health, they may in theory have a more benign effect on the course of IBD. The effects of cigarette smoking on IBD have often been attributed to nicotine, which is an ingredient in many but not all e-cigarette liquids though concentrations vary considerably. Nicotine may reduce apoptosis or influence MAP (mitogen-activated protein) kinase family and affect TNF- $\alpha$ through inhibition of nuclear factor kappa B signalling. ${ }^{16}$ Smoking has been associated with reductions in intestinal permeability. ${ }^{16}$

To date, there is limited knowledge on the smoking rates of patients with IBD compared with the general UK population and the prevalence of e-cigarette use among patients with IBD has not been studied so far. We therefore aimed to describe the current smoking habits in patients with IBD compared with general UK population including the use of e-cigarettes and study any potential effects on disease course.

\section{METHODS}

The IBD unit at Leeds Teaching Hospitals NHS Trust provides care to 4000 predominantly secondary care patients with IBD through dedicated specialist clinics. Our study was conducted as a prospective clinical audit and consecutive outpatients were prospectively recruited during IBD outpatient clinics between 14 February 2017 and 2 May 2017. Patients self-reported their smoking status including ever-smokers, current use and volume of use for cigarettes and e-cigarettes.

\section{Smoking status}

Non-smokers were defined as individuals who had never smoked, whereas ever-smokers refer to anyone with any exposure to any form of smoking (either cigarettes or e-cigarettes). Ever cigarette smoker implies past or present cigarette smoking behaviour. People who currently smoke cigarettes were classified as current smokers. Ex-smokers were defined as people who have smoked cigarettes in the past and have stopped smoking for at least 3 months. Current e-cigarette users referred to people who are currently using e-cigarettes, whereas ex e-cigarette users imply past usage of e-cigarettes (stopped for $\geq 3$ months).

\section{Clinical status and disease history}

We retrospectively collected clinical data on patients' disease characteristics and treatment history from the electronic patient management system, including demographics, disease phenotype, current and previous medication use, $\mathrm{C}$ reactive protein levels, faecal calprotectin levels, current disease activity and history of IBD-related surgery. We observed medication use among our cohort of patients by examining their current and previous use of anti-tumour necrosis factor (anti-TNF) agents (adalimumab and infliximab) and immunomodulator drugs such as thiopurines and methotrexate. We included all patients with a confirmed diagnosis of either CD or UC. Patients with indeterminate colitis or IBD unclassified were omitted from the study.

\section{Primary outcome}

The primary outcome was the comparison of the current smoking rates including the use of e-cigarettes in patients with IBD with the UK general population.

\section{Secondary outcomes}

Secondary outcomes included the association of smoking with the need for immunomodulatory drugs (thiopurine or methotrexate), the need for anti-TNF therapy (adalimumab or infliximab) and the need for surgical resection.

\section{Exploratory outcome}

We aimed to determine any association of disease-related complications (symptoms of active IBD, objective inflammation, steroid course for IBD, change of IBD maintenance medication, need for hospitalisation or surgery) 
with cigarette smoking compared with e-cigarette use during prospective follow-up.

\section{Analysis plan}

Analysis of primary outcome was performed with the self-reported patient data. Secondary outcomes were analysed with retrospective data at the time of study inclusion. For the exploratory outcome, we prospectively followed up patients for 21 months. Disease-related complications recorded included symptoms of active IBD, objective evidence of inflammation by calprotectin, endoscopy or cross-sectional imaging, requirement for steroid treatment of IBD, change in maintenance medication for IBD and hospitalisation/surgery for IBD.

Data analysis was performed using IBM SPSS 25. Patient's smoking status, demographics, IBD phenotype and disease severity were reported using descriptive statistics. Continuous variables were compared using independent $\mathrm{t}$ test, whereas categorical variables were analysed using Pearson's $\chi^{2}$ test. We considered all analysis yielding $p$ values of $<0.05$ to be statistically significant. Data of smoking habits for UK general population were gathered from Office of National Statistics 2017 for comparison.

\section{Ethics and information governance}

This study was undertaken as a prospective clinical audit and was therefore exempt from the need for research ethics committee review. ${ }^{17}$

\section{RESULTS}

Of 488 patients initially recruited, 23 cases of indeterminate colitis were excluded from further analysis. Hence, the final study cohort consisted of 465 patients, of which $58 \%$ patients had CD and $42 \%$ had UC. Mean age was 46 years, $57 \%$ were female and mean disease duration was 11 years (11.3 for $\mathrm{CD}$ and 10.5 for $\mathrm{UC}$ ). There were more female patients in general but this even more so the case for CD (61\% female) than for UC ( $52 \%$ female). Details of disease phenotype are described in table 1. Current disease activity based on physicians' assessment was remission in $39 \%$, mild in $44 \%$, moderate in $14 \%$ and severe in $3 \%$. The medical treatment history is displayed in table 2 .

\section{Smoking status}

In our cohort, 247 patients ( $53.1 \%$ ) were ever-smokers and 218 patients were non-smokers $(46.9 \%)$. Among ever-cigarette smokers, the majority of people were ex-smokers $(37.4 \%)$ followed by current smokers $(15.7 \%)$. This indicates that 174 out of 247 had quit smoking completely, whereas the rest (73) of the group continued smoking cigarettes. Ex-smokers suffering from UC had stopped on average 13 years (range $0.25-40$ years) before study inclusion, whereas ex-smokers suffering from CD had stopped on average 12 years (range $0.5-40$ years) before study inclusion. There were 28 ever e-cigarette users among our study cohort. Of this, 13 had stopped e-cigarette use and 15 had continued use of the devices. We found that all e-cigarette users in our cohort had previously smoked
Table 1 Phenotype and disease activity

\begin{tabular}{lrc}
\hline & $\mathbf{n}$ & Percentage \\
\hline Disease activity baseline & & \\
\hline Remission & 180 & 39 \\
\hline Mild & 203 & 44 \\
\hline Moderate & 69 & 14 \\
\hline Severe & 13 & 3 \\
\hline CD age (years) & & \\
\hline$<16$ & 15 & 5.6 \\
\hline 16-40 & 146 & 54.7 \\
\hline$>40$ & 106 & 39.7 \\
\hline CD location & & \\
\hline lleal & 67 & 24.9 \\
\hline Colonic & 77 & 28.6 \\
\hline lleocolonic & 124 & 46.1 \\
\hline Only upper Gl & 1 & 0.4 \\
\hline CD upper GI & 24 & 8.9 \\
\hline CD behaviour & & \\
\hline Inflammatory & 163 & 60.6 \\
\hline Stricturing & 49 & 18.2 \\
\hline Penetrating & 57 & 21.2 \\
\hline CD perianal involvement & 59 & 21.9 \\
\hline UC extent & & \\
\hline E1-proctitis & 58 & 30.2 \\
\hline E2-left sided & 78 & 40.6 \\
\hline E3-pancolitis & 56 & 29.2 \\
\hline IBD-related surgery & 140 & 30.1 \\
\hline CD, Crohn's & & \\
\hline
\end{tabular}

$\mathrm{CD}$, Crohn's disease; GI, gastrointestinal; IBD, inflammatory bowel disease; UC, ulcerative colitis.

cigarettes and stopped on average 3 years before study inclusion.

Our IBD smokers had a mean pack-year of 13.9. Table 3 shows the smoking status in our cohort. Women were more likely to smoke cigarettes than male patients (20\% vs $9 \%, \mathrm{p}=0.0015)$, whereas male patients were more likely to use e-cigarettes than women $(6 \%$ vs $1 \%$, $\mathrm{p}=0.006)$. Patients with CD were more likely to smoke cigarettes $(33.8 \%)$ compared with the UC group (19.4\%) $(\mathrm{p}=0.008)$. With regard to ever e-cigarette use, there were no statistically significant differences between $\mathrm{CD}$ and UC groups (3.6\% vs $2.4 \%) \quad(\mathrm{p}=0.948)$.

Compared with the UK general population, there were no differences in the rates of current cigarette smokers ( 15.7 vs $15.1 \%$; $\mathrm{p}=0.72$ ) but there was a statistical trend toward less current e-cigarette use than in the general population $(3.2 \%$ vs $5.5 \%$; $\mathrm{p}=0.06)$.

\section{Effect of smoking on disease course}

Current smokers were more likely to require advanced treatment for IBD (table 4). Compared with never smokers, ever exposure to immunomodulators 


\begin{tabular}{|c|c|c|}
\hline & $\begin{array}{l}\text { Crohn's } \\
\text { disease, } \\
\text { n=269 (\%) }\end{array}$ & $\begin{array}{l}\text { Ulcerative } \\
\text { colitis, } \\
\text { n=196 (\%) }\end{array}$ \\
\hline \multicolumn{3}{|l|}{ Mesalazine } \\
\hline Current & $26(9.7)$ & 154 (78.6) \\
\hline Previous & $30(8.1)$ & $23(11.7)$ \\
\hline \multicolumn{3}{|l|}{ Thiopurine } \\
\hline Current & $72(26.8)$ & $51(26)$ \\
\hline Previous & $106(37.9)$ & 25 (12.8) \\
\hline \multicolumn{3}{|l|}{ Methotrexate } \\
\hline Current & $9(3)$ & $1(0.5)$ \\
\hline Previous & $26(8.8)$ & $4(2)$ \\
\hline \multicolumn{3}{|l|}{ Infliximab } \\
\hline Current & 50 (18.6) & $10(5.1)$ \\
\hline Previous & $56(18.9)$ & $9(4.6)$ \\
\hline \multicolumn{3}{|l|}{ Adalimumab } \\
\hline Current & $42(14.2)$ & $4(2)$ \\
\hline Previous & $30(10.1)$ & $4(2)$ \\
\hline \multicolumn{3}{|l|}{ Vedolizumab } \\
\hline Current & $6(2)$ & $3(1.5)$ \\
\hline Previous & $2(0.7)$ & $1(0.5)$ \\
\hline Current steroid & $29(9.8)$ & $29(14.8)$ \\
\hline
\end{tabular}

(thiopurines and/or methotrexate) was significantly higher in current smokers ( $70 \%$ all IBD vs $56 \%, \mathrm{p}=0.049$; UC $60 \%$ vs $40 \%, \mathrm{p}=0.17$; $\mathrm{CD} 72 \%$ vs $70 \%, \mathrm{p}=0.85)$. The need for escalation to anti-TNF therapy (49\% vs $35 \%$, $\mathrm{p}=0.034$; UC $13 \%$ vs $17 \%, \mathrm{p}=1.0$; CD $55 \%$ vs $50 \%$, $\mathrm{p}=0.5$ ) and the need for IBD-related surgery (43\% vs $25 \%$, $\mathrm{p}=0.006$; UC $7 \%$ vs $10 \%, \mathrm{p}=1.0$; CD $53 \%$ vs $39 \%, \mathrm{p}=0.1$ ) were also higher in current smokers compared with never smokers when analysing retrospective data at study inclusion. We found no associations between current e-cigarette use and the need for immunomodulator therapy,

Table 3 Smoking status by disease

\begin{tabular}{llll}
\hline Status & $\begin{array}{l}\text { Crohn's } \\
\text { disease, } \\
\mathbf{n = 2 6 9}\end{array}$ & $\begin{array}{l}\text { Ulcerative } \\
\text { colitis, } \\
\mathbf{n = 1 9 6}\end{array}$ & $\begin{array}{l}\text { Significant } \mathbf{p} \\
\text { value }\end{array}$ \\
\hline $\begin{array}{l}\text { Never smoker } \\
\text { Ever-smoker }\end{array}$ & 112 & 106 & \\
$\begin{array}{l}\text { Cigarette use } \\
\text { Ex-smoker }\end{array}$ & 99 & 75 & 0.008 \\
$\begin{array}{l}\text { Current smoker } \\
\text { E-cigarette use }\end{array}$ & 58 & 15 & $<0.001$ \\
$\begin{array}{l}\text { Ex e-cigarette user } \\
\text { Current e-cigarette }\end{array}$ & 8 & 50 & \\
user & 9 & 6 & 0.948 \\
\hline
\end{tabular}

the need for anti-TNF therapy or the need for surgery; but the number of current e-cigarette users was small.

\section{Exploratory outcome}

We assessed disease-related complications during 21-month prospective follow-up in 69 cigarette smokers (53 CD, $16 \mathrm{UC}$ ) and 11 e-cigarette users (6 CD, $5 \mathrm{UC}$ ). We excluded patients without sufficient prospective follow-up data (four cigarette smokers and four e-cigarette users) from the exploratory outcome analysis. Furthermore, patients who were never smokers or had quit cigarette smoking and/or e-cigarette use were also not included. Therefore, all included patients had follow-up data for 21 months. For all IBD disease-related complications occurred only marginally more frequently in cigarette users versus e-cigarette users $(46 \%$ vs $36 \%$, $\mathrm{p}=0.74$; table 5 ). However, in patients with $\mathrm{CD}$ there was a numerically higher rate of disease-related complications in cigarette users versus e-cigarette users $(53 \%$ vs $17 \% ; \mathrm{p}=0.19$ ). The opposite was observed in the UC cohort as disease-related complications in cigarette users were numerically less frequent than in e-cigarette users ( $25 \%$ vs $60 \% ; p=0.28$ ). Of note, none of those findings were significant as the small sample size of the prospective cohort of e-cigarette users limited statistical power. Equally, we did not use time to disease complication analysis for the same reason.

\section{DISCUSSION}

Smoking, especially cigarettes, remains the single most important established environmental factor involved in IBD. There have been significant changes in smoking behaviour in the last decade in the UK and these changes have so far not been sufficiently examined. To our knowledge, our study is the first attempt to characterise smoking behaviour in the age of e-cigarette use. We have demonstrated that smoking rates in IBD have stayed in line with habits in the general population and therefore are decreasing.

Furthermore, we have elicited the rate of e-cigarette use in the IBD population for the first time. The rate of e-cigarette use is marginally lower than that in the general population. Importantly, there was no de novo use of e-cigarettes. Based on our findings it appears that patients with IBD use e-cigarettes to replace cigarette smoking or some use it as an intermediate step to full smoking cessation (13 of 28 ever e-cigarette users).

Interestingly, we saw that cigarette smoking was more prominent among female patients than in male patients. This is in contrast to the general population where males are more likely to smoke cigarettes than females. ${ }^{14}$ Our finding may relate to the higher number of females in the CD cohort, which is usually associated with higher smoking rates. Conversely, more men than women use e-cigarette-a finding in line with the general population. ${ }^{14}$ 
Table 4 Need for treatment dependant on current smoking status

\begin{tabular}{|c|c|c|c|c|c|c|}
\hline & $\begin{array}{l}\text { Immunomodulator } \\
\text { ever exposed }\end{array}$ & $\begin{array}{l}\text { Immunomodulator } \\
\text { non-exposed }\end{array}$ & $\begin{array}{l}\text { Anti-TNF } \\
\text { ever } \\
\text { exposed }\end{array}$ & $\begin{array}{l}\text { Anti-TNF non- } \\
\text { exposure }\end{array}$ & $\begin{array}{l}\text { IBD- } \\
\text { related } \\
\text { surgery }\end{array}$ & $\begin{array}{l}\text { No IBD- } \\
\text { related } \\
\text { surgery }\end{array}$ \\
\hline Never smoker & $122(56 \%)$ & $96(44 \%)$ & $76(35 \%)$ & $142(65 \%)$ & $55(25 \%)$ & $163(75 \%)$ \\
\hline $\begin{array}{l}\text { Current cigarette } \\
\text { smoker }\end{array}$ & $48(70 \%)$ & $21(30 \%)$ & 34 (49\%) & $35(51 \%)$ & $30(43 \%)$ & $39(57 \%)$ \\
\hline $\begin{array}{l}\text { Compared with } \\
\text { never smokers }\end{array}$ & & $P=0.049$ & & $P=0.034$ & & \\
\hline Current e-cigarette & $12(80 \%)$ & $3(20 \%)$ & $6(40 \%)$ & $9(60 \%)$ & $6(40 \%)$ & $9(60 \%)$ \\
\hline $\begin{array}{l}\text { Compared with } \\
\text { never smokers }\end{array}$ & & $P=0.10$ & & $P=0.78$ & & $P=0.23$ \\
\hline
\end{tabular}

IBD, inflammatory bowel disease; TNF, tumour necrosis factor.

Our study has once again demonstrated the adverse effects of smoking on $\mathrm{IBD}^{5} 13$ with a higher need for advanced therapies and/or surgery. This may largely relate to $\mathrm{CD}$, but unfortunately our overall cohort size was too small to detect meaningful associations with CD and UC separately here. We attempted to examine the effects of e-cigarettes on the course of IBD due to the small number of cases in our cohort. Our data show some interesting findings in that e-cigarette users showed numerically different rates of disease-related complications (higher in UC, lower in CD) compared with cigarette smokers. Due to our small sample size, none of these findings showed significance. The Department of Health generally recommends e-cigarettes over cigarette smoking on grounds of overall health benefits. ${ }^{18}$ Cigarette smoking in patients with non-IBD is associated with differences in the microbiome compared with non-smokers, but this was not the case for e-cigarette users. ${ }^{19}$ This observation gives rise to a study hypothesis that e-cigarette use may not exert the same effect as cigarette smoking on the bowel. Given the Department of Health recommendation, the observations in the microbiome and our findings of a numerically better disease outcomes in $\mathrm{CD}$, a large-scale prospective study ascertain whether cigarettes have any effect on the course of IBD (but especially CD) should be considered.

Table 5 Exploratory outcome: prospective assessment of disease complications

\begin{tabular}{|c|c|c|c|c|c|c|c|}
\hline & $\mathbf{n}$ & $\begin{array}{l}\text { Any disease- } \\
\text { related } \\
\text { complication }\end{array}$ & $\begin{array}{c}\text { Symptoms of } \\
\text { active IBD }\end{array}$ & $\begin{array}{c}\text { Objective } \\
\text { inflammation } \\
\text { (calprotectin, } \\
\text { endoscopy, } \\
\text { imaging) }\end{array}$ & $\begin{array}{l}\text { Steroid } \\
\text { course for } \\
\text { IBD }\end{array}$ & $\begin{array}{c}\text { Change of IBD } \\
\text { maintenance } \\
\text { medication }\end{array}$ & $\begin{array}{c}\text { Need for } \\
\text { surgery/hospital } \\
\text { admission }\end{array}$ \\
\hline \multicolumn{8}{|l|}{ All IBD } \\
\hline $\begin{array}{l}\text { Cigarette } \\
\text { smokers }\end{array}$ & 69 & 32 (46\%) & 31 (45\%) & $29(42 \%)$ & $8(12 \%)$ & 15 (22\%) & $14(20 \%)$ \\
\hline $\begin{array}{l}\text { E-cigarette } \\
\text { users }\end{array}$ & 11 & $4(36 \%)$ & $4(36 \%)$ & $3(27 \%)$ & $3(27 \%)$ & $3(27 \%)$ & 1 (9\%) \\
\hline$P$ value & & 0.74 & & & & & \\
\hline \multicolumn{8}{|l|}{ CD } \\
\hline $\begin{array}{l}\text { Cigarette } \\
\text { smokers }\end{array}$ & 53 & 28 (53\%) & 27 (51\%) & 26 (49\%) & 5 (9\%) & 14 (26\%) & 12 (23\%) \\
\hline $\begin{array}{l}\text { E-cigarette } \\
\text { users }\end{array}$ & 6 & $1(17 \%)$ & 1 (17\%) & $1(17 \%)$ & 0 & 0 & 1 (17\%) \\
\hline$P$ value & & 0.19 & & & & & \\
\hline \multicolumn{8}{|l|}{ UC } \\
\hline $\begin{array}{l}\text { Cigarette } \\
\text { smokers }\end{array}$ & 16 & 4 (25\%) & 4 (25\%) & 3 (19\%) & 3 (19\%) & $1(6 \%)$ & 2 (12\%) \\
\hline $\begin{array}{l}\text { E-cigarette } \\
\text { users }\end{array}$ & 5 & 3 (60\%) & 3 (60\%) & 2 (40\%) & 3 (60\%) & $3(60 \%)$ & 0 \\
\hline$P$ value & & 0.28 & & & & & \\
\hline
\end{tabular}

CD, Crohn's disease; IBD, inflammatory bowel disease; UC, ulcerative colitis. 
There were a number of limitations in our study. First, the study examined a cohort from a single hospital in Northern England and results may vary in different locations and with cohorts of different socioeconomic backgrounds. Unfortunately we do not have data on the socioeconomic background of our patients. Data for the general population as a comparator were taken from the official Office of National Statistics report for 2017. While these report some aspects of age or sex, the data are not available in sufficient granularity to allow for age-adjusted or sex-adjusted comparison with our cohort. Second, while the cohort is sizeable the proportion of smokers and especially e-cigarette users is relatively small and reduces the power to examine the effects of use, especially when attempting to analyse by disease subtype. Third, in this cross-sectional design we were unable to examine the effects of e-cigarette use. The main confounder is that all e-cigarette users are ex-cigarette smokers and the outcomes in question all are confounded by previous cigarette smoking. The exploratory outcome of the study is of interest but lacks the power to draw any firm conclusions.

In light of the increasing use of e-cigarettes, we propose that a prospective study examining calprotectin and clinical outcomes is urgently required to establish whether e-cigarette use is safe for patients with IBD.

Contributors CPS conceived and designed the study, supervised data collection and data analysis and wrote the draft manuscript. CC and AR collected study data, performed the primary analysis and wrote sections of the manuscript draft. RCS and KL collected study data, provided insight into the analysis and critically reviewed the manuscript.

Funding This research received no specific grant from any funding agency in the public, commercial or not-for-profit sectors.

Competing interests None declared.

Provenance and peer review Not commissioned; externally peer reviewed.

Data availability statement All data relevant to the study are included in the article or uploaded as online supplementary information.

Open access This is an open access article distributed in accordance with the Creative Commons Attribution Non Commercial (CC BY-NC 4.0) license, which permits others to distribute, remix, adapt, build upon this work non-commercially, and license their derivative works on different terms, provided the original work is properly cited, appropriate credit is given, any changes made indicated, and the use is non-commercial. See: http://creativecommons.org/licenses/by-nc/4.0/.

\section{REFERENCES}

1. Mowat C, Cole A, Windsor A, et al. Guidelines for the management of inflammatory bowel disease in adults. Gut 2011;60:571-607.

2. Knights D, Lassen KG, Xavier RJ. Advances in inflammatory bowel disease pathogenesis: linking host genetics and the microbiome. Gut 2013;62:1505-10.

3. Thomas GA, Rhodes J, Green JT, et al. Role of smoking in inflammatory bowel disease: implications for therapy. Postgrad Med J 2000;76:273-9.

4. Parkes GC, Whelan K, Lindsay JO. Smoking in inflammatory bowel disease: impact on disease course and insights into the aetiology of its effect. J Crohns Colitis 2014;8:717-25.

5. Calkins BM. A meta-analysis of the role of smoking in inflammatory bowel disease. Dig Dis Sci 1989;34:1841-54.

6. General USS. The health consequences of Smoking -50 years of progress. 2014, 2019. Available: https://www.surgeongeneral.gov/ library/reports/50-years-of-progress/full-report.pdf [Accessed $24 \mathrm{Apr}$ 2019].

7. Cosnes J, Carbonnel F, Beaugerie L, et al. Effects of cigarette smoking on the long-term course of Crohn's disease. Gastroenterology 1996;110:424-31.

8. Birrenbach T, Böcker U. Inflammatory bowel disease and smoking: a review of epidemiology, pathophysiology, and therapeutic implications. Inflamm Bowel Dis 2004;10:848-59.

9. Nunes T, Etchevers MJ, Domènech E, et al. Smoking does influence disease behaviour and impacts the need for therapy in Crohn's disease in the biologic era. Aliment Pharmacol Ther 2013;38:752-60.

10. Picco MF, Bayless TM. Tobacco consumption and disease duration are associated with Fistulizing and stricturing behaviors in the first 8 years of Crohn's disease. Am J Gastroenterol 2003;98:363-8.

11. Boyko EJ, Perera DR, Koepsell TD, et al. Effects of cigarette smoking on the clinical course of ulcerative colitis. Scand $J$ Gastroenterol 1988;23:1147-52.

12. Mokbel M, Carbonnel F, Beaugerie L, et al. [Effect of smoking on the long-term course of ulcerative colitis]. Gastroenterol Clin Biol 1998;22:858-62.

13. Lunney PC, Kariyawasam VC, Wang RR, et al. Smoking prevalence and its influence on disease course and surgery in Crohn's disease and ulcerative colitis. Aliment Pharmacol Ther 2015;42:61-70.

14. Statistics OfN, ed. Adult smoking habits in Great Britain. London, 2017.

15. Grana RA, Ling PM, Benowitz N, et al. Electronic cigarettes. Cardiology patient page. Circulation 2014;129:e490-2.

16. Lunney PC, Leong RWL. Review article: ulcerative colitis, smoking and nicotine therapy. Aliment Pharmacol Ther 2012;36:997-1008

17. Authority HR, ed. Defining research. London, 2009.

18. England PH. Evidence review of E-cigarettes and heated tobacco products 2018: Executive summary 2018, 2018. Available: https:// www.gov.uk/government/publications/e-cigarettes-and-heatedtobacco-products-evidence-review/evidence-review-of-e-cigarettesand-heated-tobacco-products-2018-executive-summary [Accessed 17 Dec 2018].

19. Stewart CJ, Auchtung TA, Ajami NJ, et al. Effects of tobacco smoke and electronic cigarette vapor exposure on the oral and gut microbiota in humans: a pilot study. PeerJ 2018;6:e4693. 